\section{ambient \\ SCIENCE \\ Vol. 04(Sp1):32-35 \\ Year 2017}

\title{
The Delineation of 'Vitamin D' Deficiency among Iranian Students: an Attempt to Establish its Potential Association with Obesity
}

\section{Marzieh Zamani', Azam Namdar ${ }^{2}$, Sareh Abdollahifard $^{3 *}$, Mina Hashemiparast ${ }^{4}$, Majid Maddahfar ${ }^{5}$}

'Department of Nutrition, School of Medicine, Jahrom University of Medical Science, Jahrom, Iran

${ }^{2}$ Department of Health, School of Medicine, Jahrom University of Medical Science, Jahrom, Iran

${ }^{3}$ Research Center for Non-communicable Diseases, Jahrom University of Medical Sciences, Jahrom, Iran

${ }^{4}$ Department of Public health, Maragheh University of Medical Sciences, Maragheh, Iran

${ }^{5}$ BHOWCO Trading GmbH, Frankfurt am Main, Germany

Study Area: Jahrom, Iran

Coordinate: $28^{\circ} 30^{\prime} \mathrm{oo}^{\prime \prime} \mathrm{N} 53^{\circ} 33^{\prime} 38^{\prime \prime} \mathrm{E}$

Keywords: Body Mass Index,

\section{Abstract}

Vitamin D def iciency is a worldwide public health problem and is recognized as a pandemic in the recent years. This cross-sectional study was conducted on a total sample of 354 students to determine the prevalence of 'Vitamin D' deficiency and its relationship with obesity among Iranian students. Data was collected using the measurement of circulating form of 25-hydroxy Vitamin D [25(OH) D] and Body Mass Index (BMI) which were further analyzed using descriptive and analytical statistics via the SPSS18 software. No significant relationship between the circulating level of vitamin D and BMI was evidenced. Only $15 \%$ of female students who had a Vitamin D deficiency, were overweight and obese, but the same frame $28.9 \%$ of the male students. Further, the prevalence of Vitamin D deficiency was significantly higher in the male students rather than females. Conclusively, the prevention, diagnosis, and treatment of Vitamin D deficiency must be important in this age group. Since no statistically signif icant relationship was found between Vitamin D deficiency and obesity, further studies are suggested to investigate this association, especially in obese people.

al., 2001). The prevalence of vitamin $\mathrm{D}$ deficiency in developing countries such as Iran, Saudi Arabia and Qatar is 20 percent higher than developed countries like Denmark and Australia (Plehwe, 2003). In Iran, the high prevalence of vitamin D deficiency has been reported in different age groups (Salek, 2007). Also, according to the findings of a study on vitamin D in Iran, there is an increasing trend of micronutrient deficiencies among individuals from 2000 to 2011 (Alizadeh et al., 2015). In recent years, the relationship between vitamin $\mathrm{D}$ deficiency and obesity has been considered and various studies have shown a significant relation between the low level of vitamin D and obesity (Mai et al., 2013; Jorde et al., 2010; Ding et al., 2010 \& Benjamin et al., 2009). In many studies obese people had a lower circulating level of 25hydroxy vitamin $\mathrm{D}$ than people with a normal weight, which seems to be the result of this fat-soluble vitamin is stored in fat tissues (Wortsman et al., 200o). On the other hand, a reduction of the circulating level of 25-hydroxy vitamin $\mathrm{D}$ leads to the loss of calcium inside adipose tissues, lip genesis and an increase in body weight (McCarty et al., 2003). Some randomized clinical trials highly prevalent (Al-Jurayyan et al., 2002; Souberbielle et

*Corresponding Author: info@sareh-abdollahi.ir 
have shown the beneficial effects of vitamin D on the regulation of body weight (Major et al., 2009). According to the World Health Organization (WHO) from 1980 to 2013, the number of people suffering from obesity has doubled in the world (WHO, 2015). Iran also faces the growing trend of this chronic disease (Arunabh et al., 2003). By keeping in mind the prevalence of vitamin D deficiency, obesity and the relationship between vitamin D deficiencies with obesity we aimed to determine the prevalence of vitamin D deficiency and its relationship with the obesity among Iranian students.

\section{Methodology:}

The present research was a descriptive cross-sectional study conducted between two group that was carried out after getting approval with IR.JUMS.REC.1394.075 and confirming by an ethics committee of Jahrom medical science university with number 1390 .

It was conducted to determine the prevalence of Vitamin D deficiency and its association with obesity. A convenience sampling technique - Random Allocation Software was used to select the participants from Jahrom University of Medical Sciences. Hence, the final sample size was calculated at 375 students. In this study, a lack of consumption of Vitamin D supplements or injection drugs during the last 6 months, having no fat malabsorption, diarrhea and chronic diseases as well as no using of anti-convulsants were the inclusion criteria. Before data collection participants were informed about the aim and method of this study and a written consent was taken (Shahla et al., 2005).

The samples in this study were first selected purposively then were divided into two groups randomly using the Random Allocation Software. In this regard, each researcher was provided a questionnaire about the inclusion criteria to the students.

Data was collected using the physical examination of 20-25 years old male and female students. For measuring height and weight, Seca scales and fabric meter attached to the wall were used. BMI was calculated by dividing the subject's mass by the square of height. To assess the circulating level of 25 -hydroxy vitamin $\mathrm{D}[25(\mathrm{OH}) \mathrm{D}]$ the ELISA method was used; in this respect, $2 \mathrm{ml}$ of venous blood was taken from each participant to measure the circulating level of Vitamin D. The blood samples were taken from 6 to 10 A.M in the laboratory. Since the normal circulating level of Vitamin D is between $30-50 \mathrm{ng} / \mathrm{ml}$, in this study the level of $<20 \mathrm{ng} / \mathrm{ml}$ and between $20-30 \mathrm{ng} / \mathrm{ml}$ was considered as Vitamin D deficiency and insuff iciency, respectively. Also, the level of $>30 \mathrm{ng} / \mathrm{ml}$ was considered as Vitamin D sufficiency. The BMI was classified into four sections: less than normal (<18.5), normal (18.5 to 24.9), overweight (25 to 29.9) and obese (>30). Data was analyzed using descriptive and analytical statistics. Chi-square test was used to assess an association between Vitamin D status and body mass index (BMI). The signif icance level for all tests was considered while $\mathrm{p}<0.05$.

\section{Results:}

Overall, 354 students consisting of 161 (45.7\%) males and $191(54.3 \%)$ females participated in the study. The mean age of the participants was 23.31 $(\mathrm{SD}=2.35)$ years. The means of the circulating level of Vitamin D were 44.5 $( \pm 29.1)$ and $27.9( \pm 15.5)$ in the female and male students, respectively. Also, the mean of BMI in the female and male students was reported as $22.04( \pm 3.4)$ and $23.3( \pm 4.0)$, respectively. With regard to the prevalence of Vitamin D deficiency (the level of $<20 \mathrm{ng} / \mathrm{ml}$ ), it was $20.9 \%$ in the female and $27.9 \%$ in the male students. The chi-square test indicated a significant relationship between gender, the level of Vitamin D and BMI (Table-1). Moreover, no significant relationship was found between the level of vitamin D and BMI between the female and male students ( $p>0.05$ ). Only 15 percent of the female students with low levels of vitamin $\mathrm{D}$ were overweight and obese, though 28.9 percent of the male students had this condition (Table-2)..

Table 1: Relationship between gender with level of Vitamin D \& BMI

\begin{tabular}{|c|c|c|c|c|c|}
\hline Variable & BMI & $\begin{array}{l}\text { Level of v } \\
(<20)^{*}\end{array}$ & $\begin{array}{l}\operatorname{tamin} D \\
(20-30)^{* *}\end{array}$ & $(>30)^{* * *}$ & $\begin{array}{l}\text { Statistics } \\
\text { Chi-sq. }\end{array}$ \\
\hline \multirow[t]{3}{*}{ Female } & $\begin{array}{l}\text { Lower than } \\
\text { normal }\end{array}$ & $5(12.5)$ & $2(5.4)$ & $10(8.8)$ & \multirow[t]{3}{*}{$4 \cdot 44$} \\
\hline & Normal & $29(72.5)$ & $33(89.2)$ & $87(76.3)$ & \\
\hline & $\begin{array}{l}\text { Overweight } \\
\text { Obese }\end{array}$ & $\begin{array}{l}4(10.0) \\
2(5.0)\end{array}$ & $\begin{array}{l}1(2.7) \\
1(2.7)\end{array}$ & $\begin{array}{l}13(11.4) \\
4(3 \cdot 5)\end{array}$ & \\
\hline \multirow[t]{4}{*}{ Male } & $\begin{array}{l}\text { Lower than } \\
\text { normal }\end{array}$ & $4(8.9)$ & $5(7 \cdot 7)$ & $3(5 \cdot 9)$ & \multirow[t]{4}{*}{$3 \cdot 36$} \\
\hline & Normal & $28(62.2)$ & $38(58.5)$ & $34(66.7)$ & \\
\hline & Overweight & $9(20.0)$ & $18(27.7)$ & $13(25 \cdot 5)$ & \\
\hline & Obese & $4(8.9)$ & $4(6.2)$ & $1(2.0)$ & \\
\hline $\mathrm{p}>0.05$ & \multicolumn{5}{|c|}{ *Deficiency, ${ }^{* *}$ Insufficient, } \\
\hline
\end{tabular}

In general, the positive and significant association was seen between age and MetS morbidity ( $\mathrm{p}<0.001, \mathrm{r}=0.287$ ). However, this association was not significant in Turkman group. Age cut-off values for predicting MetS was 33.5 years in Turkman, 50.5 years in non-Turkman and 42.5 years in total of subjects. (Table 2 ) The AUCs ranged from 0.546 in Turkman group to 0.726 for non-Turkman group. The values for AUC tended to be higher in non-Turkman and in total of subjects. (Graphı).

\section{Discussion and conclusions:}

As per our survey, there is no statistically significant relationship was revealed between the serum level of Vitamin D and BMI. Conversely, Arunabh et al., (2003) showed a statistically significant relationship between obesity and a low level of Vitamin D. According to two 
Ambient Science, 2017: Vol. 04(Sp1); 32-35

DOI:10.21276/ambi.2017.04.sp1.ra03

RESEARCH ARTICLE

Table 2: The relationship between the level of vitamin D and BMI among females and males

\begin{tabular}{l|lll|llll|l}
\hline Variable & \multicolumn{3}{|c|}{ Level of vitamin D } & \multicolumn{4}{c|}{ BMI } & p value \\
$\mathrm{N}(\%)$ & $(<20)^{*}$ & $(20-30)^{* *}$ & $(>30)^{* * *}$ & $(<18.5)^{\mathrm{a}}$ & $(18.9-24.9)^{\mathrm{b}}$ & $(25-29.9)^{\mathrm{c}}$ & $(>30)^{\mathrm{d}}$ & \\
\hline Female & $40(20.9)$ & $37(19.4)$ & $114(59.7)$ & $12(7.5)$ & $100(62.1)$ & $40(24.8)$ & $9(5.6)$ & \\
Male & $45(27.9)$ & $65(40.4)$ & $51(31.7)$ & $17(8.9)$ & $149(78.0)$ & $18(9.4)$ & $7(3.7)$ & \\
Chi squared & $29.69^{*}$ & & & & $1.66^{*}$ & & $<0.05$ \\
\hline
\end{tabular}

${ }^{*}$ Deficiency, ${ }^{* *}$ Insufficient, ${ }^{* * *}$ Sufficient;

${ }^{\mathrm{a}}$ Lower than normal, ${ }^{\mathrm{b}}$ Normal, 'Overweight, ${ }^{\mathrm{d}}$ Obese

cohort studies conducted on North Americans and African Americans, the increased fat mass and body mass index had statistically significant association with Vitamin D deficiency (Devaraj et al., 2011 \& Aloia et al., 2008). Another study conducted on menopause women in high altitude areas in England also showed that the production of Vitamin D in the body of individuals with the BMI higher than 34 was 10\% lower as those people with a normal weight (Macdonald et al., 2008). Other studies around the world reflected the relationship between Vitamin D deficiency and obesity compared with normal weight people. For instance, in a study by Forrest et al. (2011) on adult population in America, the prevalence of Vitamin D deficiency in obese people was reported at about twice normal weight adults. In other Iranian studies, the relationship between the serum levels of Vitamin D and obesity was reported. In a study on women 15 -49 years old in Tabriz, statistically significant correlations were observed between the levels of Vitamin D and weight and BMI (Alshahrani et al., 2014).

Some other studies have shown controversial findings with regard to the relationship between obesity, being overweight, and Vitamin D. For instance, in a study conducted on 3669 healthy adults living in five large cities in Iran, statistically significant relationship was not found between BMI and Vitamin D (Khashayar et al., 2013). Karimi et al. (2014) studied the prevalence of Vitamin D deficiency, BMI and waist circumference in female adolescents aged 14-17 years old in Bokan city, Iran and found no such relationship. Such contradictions in the findings of these studies stem from differences in the methodology, samples and methods used to measure 25hydroxyvitamin D. Since the findings of cross-sectional studies do not suggest a causal link, there are also needs for conducting cohort studies, clinical trials and systematic reviews, and meta-analysis for conf irming the results.

We also found that there was a statistically signif icant relationship between gender and Vitamin D as the male students had more vitamin D deficiency compared to the female students. Other studies reported that female students suffered more from Vitamin D deficiency in comparison with their male counterparts. In a study on the association between Vitamin D deficiency and cardiovascular disorders on 547 female and male people aged between 30 and 60 years old, the majority of females suffered from cardiovascular disorders (El-Menyar et al., 2012). According to the findings of another study, on male and female students aged 18-33 years from the Middle East and living in London, Ontario and Canada, the prevalence of vitamin D deficiency was higher in female students (Alshahrani, 2014). A study conducted in Iran in between 2000 to 2011 reflected the severe Vitamin D deficiency in women while compared to men (Saeedinia et al., 2013). Despite these conflicting results, some studies found the higher level of Vitamin D def iciency in males than females (Johnson et al., 2012). In the study by Johnsom et al. (2012) with 2026 participants, the prevalence of vitamin D was reported higher in males than females. One limitation of this study was a lack of data collection on the amount of Vitamin D from food intake and the accurate calculation of hours of exposure to sunlight. Also, since one of the factors affecting serum levels of vitamin D is individuals' genetics such an assessment was impossible.

Surprisingly, in our study, we found a drastic difference in the means of the circulating level of Vitamin $\mathrm{D}$ recorded between male and female. However, in the present scenario, we are not in a position to forward any concrete reason to support our abrupt data, but we could speculate that during the time of our sample collection, most of the males participated in our study were not even taken their breakfast, and we were having no other alternative time to collect the samples. Probably taking a sample of the subjects (male) in their empty bowl conditions could be the reason why they show poor Vitamin D.

Conclusively, weekly exposure to sunlight and the use of foods containing vitamin D in diet programs are suggested. Since no statistically significant relationship was found between vitamin D deficiency and obesity, further studies are suggested to investigate this association, especially in obese people.

Acknowledgements:

This original study was supported financially by Jahrom University of Medical Sciences, Jahrom, Iran. The authors would like to express their gratitude to the participants for their active participation in this study.

\section{References:}

Alizadeh, Z., Halabchi, F. \& Tabesh M.R. (2015): Vitamin D def iciency in population with BMI greater than $25 \mathrm{~kg} / \mathrm{m} 2$ and its association with demographic and anthropometric 
indices. Tehran Univ. Med.J., 73(6):447-455.

Al-Jurayyan, N.A., El-Desouki, M.E., Al-Herbish, A.S., Al-Mazyad, A.S. \& Al-Qhtani, M.M. (2002): Nutritional rickets and osteomalacia in school children and adolescents. Saudi Med. L.,23:182-185.

Aloia, J.F. (2008): African Americans, 25-hydroxyvitamin D, and osteoporosis: a paradox.Am. J. Clin. Nutr., 88(2):545S-55oS

Alshahrani, A. (2014): Vitamin D Deficiency and Possible Risk Factors Among Middle Eastern University Students in London. Ontario, Canada. Thesis for Master degree submitted:The University of Western Ontario. p. 94

Ostad, R.A., Zarghami, N., Sadighi, A., Alani, B. \& Dostzadeh, A. (2006): Prevalence of Vitamin D Deficiency and Some of its Risk Factors in Reproductive Age Women in Tabriz. Med. J. Tabriz Uni. Med. Sci., 27(4): 7-11

Arunabh, S., Pollack, S., Yeh, J. \& Aloia, J.F. (2003): Body fat content and 25-hydroxyvitamin D levels in healthy women. J. Clin. Endocrinol. Metab.,88(1):157-161.

Benjamin, A., Moriakova, A., Akhter, N., Rao, D., Xie, H., Kukreja, S. \& Barengolts, E. (2009): Determinants of 25hydroxyvitamin D levels in African-American and Caucasian male veterans. Osteoporos Int., 20(10):1795-1803.

Cantorna, M.T., Zhu, Y., Froicu, M. \& Wittke, A. (2004): Vitamin D status, 1, 25-dihydroxyvitamin $\mathrm{D}_{3}$, and the immune system. Am.J. Clin. Nutr., 8o(6):1717-1720.

Devaraj, S., Jialal, G., Cook, T., Siegel, D., Jialal, I. (2011): Low vitamin D levels in Northern American adultswith the metabolic syndrome. Horm. Metab. Res. . 43(01):72-74.

Ding, C., Parameswaran, V., Blizzard, L., Burgess, J. \& Jones, G. (2010): Not a simple fat-soluble vitamin: changes in serum 25 $(\mathrm{OH}) \mathrm{D}$ levels are predicted by adiposity and adipocytokines in older adults. J. Intern. Med., 268(5):501-510.

El-Menyar, A., Rahil, A., Dousa, K., Ibrahim, W., Ibrahim, T., Khalifa, R. \& Rahman, M.O.A. (2012): Low vitamin D and cardiovascular risk factors in males and females from a sunny, rich country. Open Cardiovasc. Med. J., 6:76-80.

Forrest, K.Y. \& Stuhldreher, W.L. (2011): Prevalence and correlates of vitamin D def iciency in US adults. Nutr. Res. 31(1):48-54.

Garland, C.F., Garland, F.C., Gorham, E.D., Lipkin, M., Newmark, H., Mohr SB. \& Holick MF. (2006): The role of vitamin D in cancer prevention. Am. J. Public Health, 96(2):252-261.

Holick, M.F. \& Chen, T.C. (2008): Vitamin D deficiency: a worldwide problem with health consequences. Am. J. Clin. Nutr., 87(4):1080-1086.

Hosseinpanah, F., Barzin, M., Eskandary, P.S., Mirmiran, P. \& Azizi, F. (2009): Trends of obesity and abdominal obesity in Tehranian adults: a cohort study. BMC Pub. Health, 9:426.

Johnson, L., Hofsø, D., Aasheim, E., Tanbo, T., Holven, K., Andersen, L., Røislien, J. \& Hjelmesæth, J. (2012): Impact of gender on vitamin D deficiency in morbidly obese patients: a cross-sectional study. Eur. J. Clin. Nutr., 66(1):83-90.

Jorde, R., Sneve, M., Emaus, N., Figenschau, Y., Grimnes, G. (2010): Cross-sectional and longitudinal relation between serum 25hydroxyvitamin D and body mass index: the Tromsø study. Eur. J. Nutr., 49(7):401-407.

Karimi-Hasanabad, S., Rafraf, M. \& Asghari-Jafarabadi, M. (2014): Prevalence of vitamin d deficiency and its relationship with body mass index and waist circumference in female adolescents 17-14 years, boukan. Iran. J. Diabetes Metab.,
14(1):55-62.

Khashayar, P., Meybodi, H., Soltani, A., Taheri, E., Homami, M.R., Heshmat, R. Dimai, H.P. \& Larijani, B. (2013): Association between vitamin D levels and BMI values in an Iranian population. Clin. Lab., 6o(3):383-389.

Macdonald, H.M., Mavroeidi, A., Barr, R.J., Black, A.J., Fraser, W.D. \& Reid, D.M. (2008): Vitamin D status in postmenopausal women living at higher latitudes in the UK in relation to bone health, overweight, sunlight exposure and dietaryvitamin D. Bone. 42(5):996-1003.

Mai, X-M, Chen,Y., Camargo, C.A. \& Langhammer, A. (2012): Cross-Sectional and Prospective Cohort Study of Serum 25Hydroxyvitamin D Level and Obesity in Adults The HUNT Study. Am. J. Epidemiol., 175(10):1029-1036.

Major, G.C., Alarie, F.P., Doré, J., Tremblay, A. (2009): Calcium plus vitamin D supplementation and fat mass loss in female very low-calcium consumers: potential link with a calciumspecif ic appetite control. Br.J. Nutr., 101(05):659-663.

McCarty, M. \& Thomas, C. (2003): PTH excess may promote weight gain by impeding catecholamine-induced lipolysisimplications for the impact of calcium, vitamin $\mathrm{D}$, and alcohol on body weight. Med. Hypotheses, 61(5):535-542.

McGrath, J., Selten, J.P. \& Chant, D. (2002): Long-term trends in sunshine duration and its association with schizophrenia birth rates and age at first registrationdata from Australia and the Netherlands. Schizophr Res., 54(3):199-212.

Plehwe, W.E. (2003): Vitamin D deficiency in the 21st century: an unnecessary pandemic? Clin. Endocrinol.,59(1):22-24.

Saeedinia, A., Larijani, B., Jalalinia, S., Farzadfar, F., Keshtkar, A. \& Rezaee, E. (2013): Prevalance of Vitamin D deficiency among adult population of Islamic Republic of Iran throghout 1990-2010. Iran. J. Diabet. Lipid Dis., 12(6):574-584.

Salek, M., Rafati, H., Hashemipour, M., Ardestani, P.M., Nezhadnik, H., Amini, M., (2007): Is Vitamin D Deficiency Prevalent in Healthy 6-yearold Children in Isfahan City? L. Isfahan Med. School, 25(85): 95-103.

Shahla, A., CharehSaz, S., Talebi, R. \& Azad, E. (2005): Vitamin D def iciency in 15-40 years old females in Urmia. Urmia Med.J., 16:80-83; (in Persian).

Shakiba, M. \& Rafiei, P. (2009): Prevalence of Vitamin D Deficiency Among Medical Staff in Shahid Sadoughi Hospital in Yazd, Iran. L. Toloo-ebehdasht, 7(3):22-30.

Souberbielle, J.C., Cormier, C., Kindermans, C., Gao, P., Cantor, T., Forette, F. \& Baulieu, E.E. (2001): Vitamin D Status and Redef ining Serum Parathyroid Hormone Reference Range in the Elderly.J. Clin. Endocrinol. Metab., 86(7):3086-3090.

Talaei, A., Mohamadi, M. \& Adgi, Z. (2013): The effect of vitamin D on insulin resistance in patients with type 2 diabetes. Diabetol. Metab. Syndr., 5(1):8

Talaei, A., Yadegari, N., Rafee, M. \& Rezvanfar, M. (2011): Vitamin D Def iciency and Its Cut-off Point among Young Teenagers. L.Birjand University, 18(3):210-216.

WHO (World Health Organization) (2015): Obesity and Overweight. Fact sheet $\mathrm{N}^{\circ} 311$.

Wortsman, J., Matsuoka, L.Y., Chen, T.C., Lu, Z. \& Holick, M.F. (200o): Decreased bioavailability of vitamin D in obesity. Am. J. Clin. Nutr.,72(3):69o-693. 